\title{
A simple method to detect expiratory flow limitation during spontaneous breathing
}

\author{
N.G. Koulouris*, P. Valta*, A. Lavoie*, C. Corbeil**, M. Chassé**, \\ J. Braidy**, J. Milic-Emili*
}

A simple method to detect expiratory flow limitation during spontaneous breathing. N.G. Koulouris, P. Valta, A. Lavoie, C. Corbeil, M. Chassé, J. Braidy, J. Milic-Emili. @eERS Journals Ltd 1995.

ABSTRACT: Patients with severe chronic obstructive pulmonary disease (COPD) often exhale along the same flow-volume curve during quiet breathing as during a forced expiratory vital capacity manoeuvre, and this has been taken as indicating flow limitation at rest. To obtain such curves, a body plethysmograph and the patient's co-operation are required.

We propose a simple technique which does not entail these requirements. It consists in applying negative pressure at the mouth during a tidal expiration (NEP). Patients in whom NEP elicits an increase in flow throughout the expiration are not flow-limited. In contrast, patients in whom application of NEP does not elicit an increase in flow during most or part of the tidal expiration are considered as flowlimited. Using this technique, 26 stable COPD patients were studied sitting and supine.

Eleven patients were flow-limited both seated and supine, eight were flow-limited only when supine, and seven were not flow-limited either seated or supine. Only 5 of 19 patients who were flow-limited seated and/or supine had severe ventilatory impairment (forced expiratory volume in one second $\left(\mathrm{FEV}_{1}\right)<\mathbf{4 0 \%}$ predicted).

We conclude that the NEP technique provides a simple, rapid, and reliable method for detection of expiratory flow limitation in spontaneously breathing subjects, which does not require the patient's co-operation, and can be applied in different body positions both at rest and during muscular exercise. Our results also indicate a high prevalence of flow limitation in COPD patients at rest, particularly when supine. Eur Respir J., 1995, 8, 306-313.

\author{
*Meakins-Christie Laboratories, McGill \\ University, Montreal, Quebec, Canada. \\ **Respiratory Division, Saint-Luc Hospital, \\ Montreal, Quebec, Canada.
}

Correspondence: J. Milic-Emili Meakins-Christie Laboratories

McGill University

3626 St. Urbain Street

Montreal

Quebec H2X 2P2

Canada

\section{Keywords:}

Chronic obstructive pulmonary disease expiratory flow limitation at rest negative expiratory pressure posture

respiratory mechanics

Received: February 21994

Accepted after revision October 131994

This study was supported by the Medical Research Council of Canada and by the J.T. Costello Memorial Research Fund, Royal Victoria Hospital Foundation.
It has long been suggested that patients with severe chronic obstructive pulmonary disease (COPD) may exhibit expiratory flow limitation at rest, as reflected by the fact that they breathe tidally along or above their maximum expiratory flow-volume curves [1-3]. The effects of expiratory flow limitation may be partly compensated by breathing at lung volumes higher than the relaxation volume of the respiratory system [3]. The latter condition, which is termed dynamic pulmonary hyperinflation, is associated with intrinsic positive endexpiratory pressure (PEEPi) [4]. The combined effects of increased flow resistance, dynamic hyperinflation and PEEPi place a severe burden on the inspiratory muscles of COPD patients [5-7], and may also contribute to dyspnoea [8].

Though dynamic hyperinflation is the hallmark of expiratory flow limitation, the prevalence and clinical significance of this phenomenon have not been adequately studied in ambulatory COPD patients. Indeed, direct assessment of expiratory flow limitation requires determination of isovolume relationships between flow and transpulmonary pressure $(\dot{\mathrm{V}}-\mathrm{P})$, an approach which is technically complex, time-consuming and invasive, because it requires measurement of oesophageal pressure [1-3]. As a result, detection of flow limitation is generally based on comparison of tidal and maximal flowvolume (ن-V) curves, as proposed by HyATт in 1961 [1]. Like HyATT [1], nearly all clinical and many research laboratories conventionally use expired gas volume for the determination of $\dot{V}-\mathrm{V}$ curves, though as early as 1966 INGRAM and SCHILDER [9] pointed out that, as a result of gas compression during the forced expiratory vital capacity (FVC) manoeuvres, the $\dot{\mathrm{V}}-\mathrm{V}$ curves should actually be measured with a body plethysmograph.

However, apart from the latter requirement, there are additional factors which make assessment of flow limitation based on comparison of tidal and maximal $\dot{\mathrm{V}}-\mathrm{V}$ curves problematical: 1) changes in airway resistance and static lung recoil due to the maximal inspiration prior to the FVC manoeuvre [10]; and 2) time-dependent lung emptying due to time-constant inequality [11], and viscoelastic forces [12] within the lung. These mechanisms imply that the magnitude of the flow during forced expiration should depend markedly on the volume and 
time history of the inspiration preceding the FVC manoeuvre, as recently shown in COPD patients by D'ANGELO et al. [12]. Since, by definition, the previous volume and time history varies between resting breathing and a maximal inspiration, it follows that assessment of flow limitation based on comparison of tidal and maximal $\dot{\mathrm{V}}$ $\mathrm{V}$ curves may lead to erroneous conclusions, even if the measurements are obtained using body plethysmography.

Recently, however, VALTA et al. [13] have introduced an alternative technique (negative expiratory pressure (NEP) method) to detect expiratory flow limitation, which does not require performance of forced expiratory efforts on the part of the patient, nor a body plethysmograph. It consists in applying a negative pressure at the mouth during a resting tidal expiration and comparing the ensuing expiratory $\dot{V}-\mathrm{V}$ curve with that of the previous control expiration. Thus, with this technique, the volume history of the control expiration and of the subsequent expiration with NEP is the same. The NEP technique for detecting expiratory flow limitation has previously been applied and validated by concomitant determination of isovolume $\dot{\mathrm{V}}-\mathrm{P}$ relationships in intensive care unit (ICU) patients during controlled mechanical ventilation [13].

In the present study, using the NEP technique, we have assessed the prevalence of expiratory flow limitation during resting breathing in a group of stable COPD patients with varying degrees of airways obstruction. The measurements were made both in sitting and supine positions. In sitting position, we have also assessed flow limitation with the conventional method based on comparison of tidal and maximal expiratory $\dot{\mathrm{V}}-\mathrm{V}$ curves.

\section{Material and methods}

We studied 26 ambulatory Caucasian patients (16 males and 10 females), mean ( $\pm \mathrm{SD})$ age $65 \pm 10$ yrs (range 42 $87 \mathrm{yrs}$ ), weight (\% predicted) [14] 110 $21 \%$ (69-156\%), and height $164 \pm 9 \mathrm{~cm}(147-183 \mathrm{~cm})$. All subjects had COPD ranging from mild to severe, with forced expiratory volume in one second $\left(\mathrm{FEV}_{1}\right)(\%$ pred) of $60 \pm 22 \%$ (range $22-98 \%$ pred) and $\mathrm{FEV}_{1} /$ forced vital capacity (FVC) (\%) 54 $\pm 14 \%$ (range 27-79\%). All were in a stable clinical and functional state, and were recruited from the respiratory out-patient clinic. Their lung function data were obtained in seated position with a pressure/flow whole body plethysmograph (Autobox 2800; Sensormedics Inc., Yorba Linda, CA, USA). Predicted lung function values were those of MorRIs et al. [15]. The above routine lung function measurements also included determination of tidal and maximal expiratory $\dot{\mathrm{V}}-\mathrm{V}$ curves in sitting position at rest. As is common practice in most lung function laboratories, these curves were based on expired gas volume obtained by integration of flow at the mouth. Arterial oxygen tension $\left(\mathrm{PaO}_{2}\right)$ and arterial carbon dioxide tension $\left(\mathrm{PaCO}_{2}\right)$ were measured with a blood gas analyser (ABL 330; Radiometer, Copenhagen, Denmark). The study was approved by the local Ethics Committee. All subjects gave informed consent.

Figure 1 depicts the experimental set-up used to assess expiratory flow limitation. A flanged plastic mouthpiece

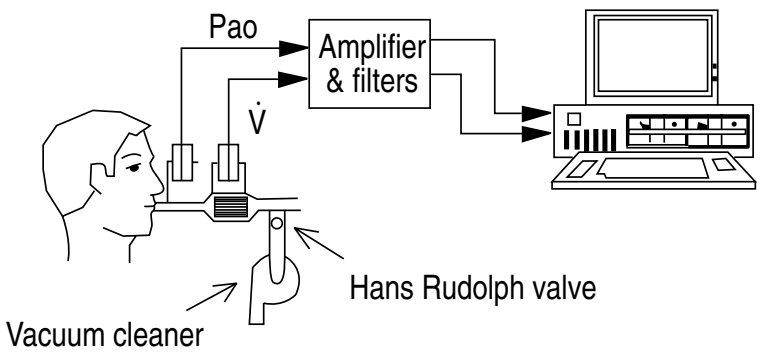

Fig. 1. - Schematic diagram of equipment set-up. Pao: pressure at airways opening; $\dot{\mathrm{V}}$ : gas flow.

is connected in series to a Fleisch No. 2 pneumotachograph (Fleisch, Lausanne, Switzerland) and a T-tube. One side of the T-tube is open to the atmosphere, whilst the other side is equipped with a one-way pneumatic valve which allows for the subject to be rapidly switched to negative pressure generated by a vacuum cleaner (Hoover Heavy Duty Portapower, Model S7065-060; The Hoover Co., OH, USA). The pneumatic valve (Occlusion valve set-up, Series 9300; Hans Rudolph, Inc., Kansas City, MO, USA) consists of an inflatable-balloon connected to a gas cylinder and a manual pneumatic controller (Hans Rudolph control switch, 9301). The latter permits remote-control balloon deflation, which is accomplished quickly (30-60 ms) and quietly, allowing rapid exposure to negative pressure during expiration (NEP). The NEP (usually set at about $-5 \mathrm{cmH}_{2} \mathrm{O}$ ) could be adjusted with a potentiometer (Powerstat; The Superior Electric Co., CT, USA).

Airflow (V) was measured with the heated Fleisch No. 2 pneumotachograph, connected to a differential pressure transducer (Validyne MP45, $\pm 2 \mathrm{cmH}_{2} \mathrm{O}$; Validyne Co., Northridge, CA, USA). This is one of the most symmetrical transducers presently available, with a common-mode rejection ratio (CMRR) of $70 \mathrm{~dB}$ at $30 \mathrm{~Hz}$ [16]. The pneumotachograph system was linear over the range of flows used. Pressure at the airway opening (Pao) was measured through a side-port on the mouthpiece, using a differential pressure transducer (Validyne $\left.\mathrm{MP} 45, \pm 88 \mathrm{cmH}_{2} \mathrm{O}\right)$. The transducer was calibrated before and after each study with a water manometer. With this system, there was no appreciable shift or alteration in pressure amplitude up to $20 \mathrm{~Hz}$. The breathing assembly had a dead space of $90 \mathrm{ml}$, and a pressure-flow relationship characterized by the following equation:

$$
\mathrm{P}=0.42 \dot{\mathrm{V}}+0.35 \dot{\mathrm{V}}^{2}\left(\mathrm{r}^{2}=0.999\right)
$$

where pressure is in $\mathrm{cmH}_{2} \mathrm{O}$ and flow in $l \cdot \mathrm{s}^{-1}$. The flow and pressure signals were amplified (amplifier No.8085; Hewlett-Packard, Waltham, MA, USA) and sampled simultaneously at a rate of $100 \mathrm{~Hz}$, using a computer data acquisition system with a built-in 16-bit analog-todigital converter (AT-Codas; DATAQ instruments, Inc., Akron, OH, USA). Collected data were stored on computer disk for subsequent analysis. Volume (V) was obtained by numerical integration of the flow signal. The flow signal was corrected for any offset, using the assumption that inspired and expired volume of the control breaths preceding the test breaths were the same [17]. 
This analysis was made using ANADAT data analysis software (version 5.1; RHT-InfoDat Inc., Montreal, Quebec, Canada).

\section{Procedure}

Subjects were studied in a random order while seated upright in a comfortable chair or laying supine on a comfortable couch, at least $2 \mathrm{~h}$ after eating or taking coffee. They were asked to breathe room air through the equipment assembly (fig. 1) with the noseclip on. Each subject had an initial 10-15 min trial run, in order to become accustomed to the apparatus and procedure. The pneumotachogram was continuously monitored on the screen of the computer. When regular breathing had been achieved, we performed a series of test breaths, in which NEP (about $-5 \mathrm{cmH}_{2} \mathrm{O}$ ) was applied at the beginning of expiration and maintained throughout the ensuing expiration.

Statistical analysis was made using one-way analysis of variance (ANOVA) and Student-Neuman-Keuls test of multiple comparisons. A value of $\mathrm{p}<0.05$ was taken as statistically significant.

\section{Results}

Figure 2a shows a representative record of flow, volume and Pao obtained during a control and a NEP test breath in a COPD patient in sitting position. Application of NEP resulted in an increase of expiratory flow,

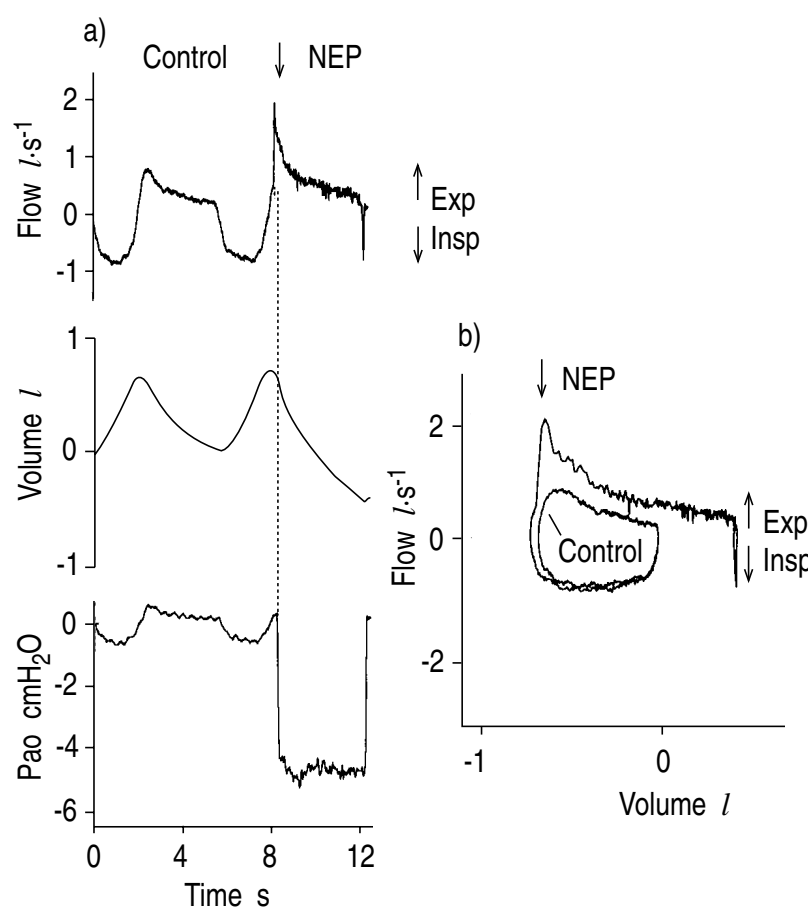

Fig. 2. - a) Records of flow, volume and pressure at airway opening (Pao) from a seated COPD patient during a control breath, followed by a test breath during which negative pressure (NEP) was applied at the onset of expiration (indicated by arrow) and maintained throughout the expiration. b) Flow-volume loops corresponding to (a). Compared to control, during the test breath with NEP there is a substantial increase in flow throughout the ensuing expiration. COPD: chronic obstructive pulmonary disease; Exp: expiration; Insp: inspiration.

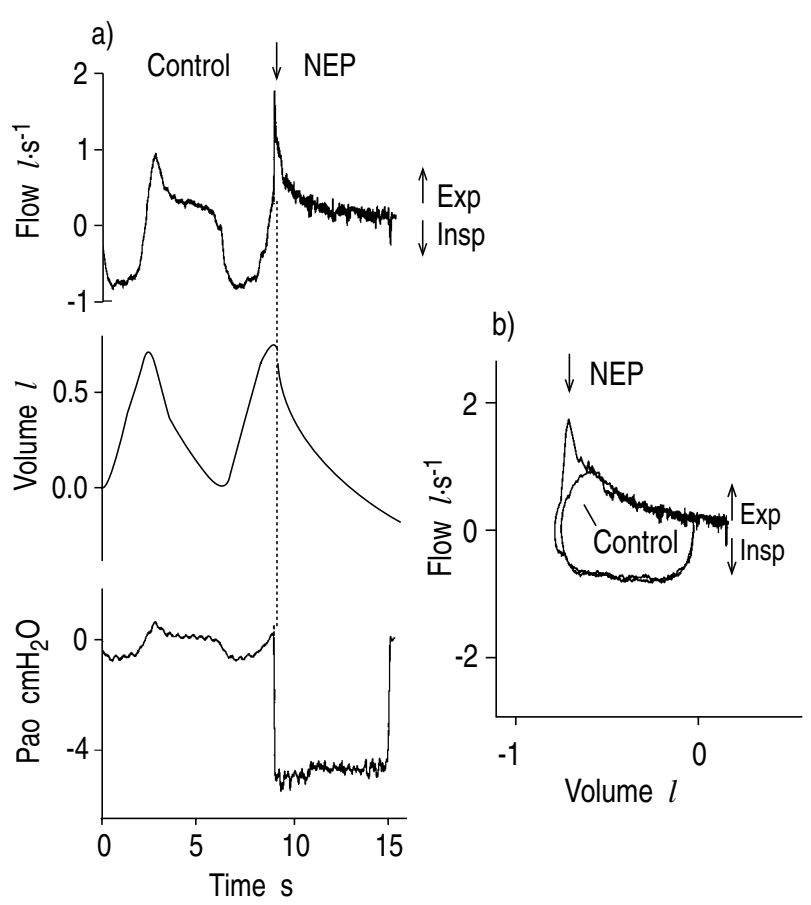

Fig. 3. - Similar records to those in figure 2 in same subject but supine. In this instance the expiratory flow of the test breath did not change relative to control, except for a transient increase at the onset of the expiration with NEP. For abbreviations see legend to figure 2 .

as reflected by the more rapid decay of lung volume following the application of the NEP. The increase in expiratory flow with NEP is also shown in figure $2 b$, which depicts the superimposed loops of the NEP test breath and of the preceding control breath. NEP resulted in increased flow over the entire range of the control tidal expiration, indicating that in this patient there was no flow limitation during resting breathing in seated position. As a result of the suction due to NEP, the expired tidal volume was greater than the corresponding control value (1.14 vs $0.67 \mathrm{l}$ ), though the durations of expiration were similar.

When the patient from figure 2 was studied in supine position, he became flow-limited, because the application of NEP did not result in an increase of expiratory flow during most of expiration (fig. 3). Only at the onset of expiration was there an increase in the flow of the test breath. This initial non-flow-limited range amounted to $18 \%$ of the control tidal volume, whilst the flowlimited range corresponded to the remaining $82 \%$. Though the patient was flow-limited in supine position, application of NEP still resulted in a expired volume greater than control $(0.96 v s 0.70 l)$. This was due, in part, to the transient increase in flow at the onset of the expiration with NEP and, more importantly, to the fact that NEP was applied in this instance for about $5 \mathrm{~s}$, whilst the duration of the control expiration was only $4 \mathrm{~s}$.

Eleven of our 26 COPD patients were flow-limited both seated and supine, eight were flow-limited only supine, and seven were not flow-limited either seated or supine. It should be noted that there was no patient who was flow-limited seated but not supine. In all patients, the results were reproducible with repeated NEP tests. 
Table 1. - Anthropomentric and lung function data of the three groups of stable COPD patients

\begin{tabular}{|c|c|c|c|c|}
\hline & $\begin{array}{c}\text { Non } \\
\text { flow-limited } \\
\mathrm{n}=7\end{array}$ & $\begin{array}{c}\text { Flow-limited } \\
\text { only when supine } \\
n=8\end{array}$ & $\begin{array}{c}\text { Flow-limited } \\
\text { seated and supine } \\
\mathrm{n}=11\end{array}$ & $\begin{array}{r}\text { ANOVA } \\
\text { all groups } \\
\end{array}$ \\
\hline Age yrs & $61 \pm 5$ & $65 \pm 10$ & $66 \pm 12$ & $\mathrm{p}<0.51$ \\
\hline Height $\mathrm{cm}$ & $161 \pm 8$ & $167 \pm 11$ & $163 \pm 8.5$ & $\mathrm{p}<0.46$ \\
\hline Weight $\%$ pred & $109 \pm 28$ & $107 \pm 13$ & $114 \pm 22$ & $p<0.74$ \\
\hline $\operatorname{Sex} M / F$ & $4 / 3$ & $5 / 3$ & $8 / 4$ & \\
\hline FVC $\%$ pred & $93 \pm 5$ & $84 \pm 14$ & $62 \pm 15^{* * * *}$ & $\mathrm{p}<0.001$ \\
\hline $\mathrm{FEV}_{1} \%$ pred & $82 \pm 12$ & $63 \pm 13^{*}$ & $44 \pm 19 * * *$ & $\mathrm{p}<0.001$ \\
\hline $\mathrm{FEV}_{1} / \mathrm{FVC} \%$ & $63 \pm 9$ & $54 \pm 13$ & $49 \pm 14$ & $\mathrm{p}<0.076$ \\
\hline FRC $\%$ pred & $115 \pm 27$ & $\begin{array}{c}146 \pm 25^{*} \\
\mathrm{n}=7\end{array}$ & $176 \pm 36^{* *}$ & $\mathrm{p}<0.002$ \\
\hline TLC $\%$ pred & $109 \pm 12$ & $\begin{array}{c}126 \pm 12 * \\
\mathrm{n}=7\end{array}$ & $138 \pm 20 * *$ & $\mathrm{p}<0.004$ \\
\hline $\mathrm{RV} \%$ pred & $117 \pm 32$ & $\begin{array}{c}175 \pm 35 * * \\
\mathrm{n}=7\end{array}$ & $232 \pm 59 * * *$ & $\mathrm{p}<0.001$ \\
\hline RV/TLC \% & $40 \pm 8$ & $\begin{array}{c}55 \pm 8 * * \\
\mathrm{n}=7\end{array}$ & $65 \pm 10 * * *$ & $\mathrm{p}<0.001$ \\
\hline $\mathrm{PaO}_{2} \mathrm{kPa}$ & $\begin{array}{c}11.0 \pm 1.1 \\
\mathrm{n}=6\end{array}$ & $\begin{array}{c}10.2 \pm 1.4 \\
\mathrm{n}=6\end{array}$ & $\begin{array}{c}9.0 \pm 0.9 * * \\
\mathrm{n}=8\end{array}$ & $\mathrm{p}<0.014$ \\
\hline $\mathrm{PaCO}_{2} \mathrm{kPa}$ & $\begin{array}{c}5.0 \pm 0.5 \\
n=6\end{array}$ & $\begin{array}{c}5.5 \pm 0.6 \\
n=6\end{array}$ & $\begin{array}{c}5.7 \pm 0.5 \\
n=8\end{array}$ & $\mathrm{p}<0.11$ \\
\hline
\end{tabular}

Data are presented as mean \pm SD. COPD: chronic obstructive pulmonary disease; M: male; F: female; FVC: forced vital capacity; $\%$ pred: percentage of predicted; $\mathrm{FEV}_{1}$ : forced expiratory volume in one second; FRC: functional residual capacity; TLC: total lung capacity; $\mathrm{RV}$ : residual volume; $\mathrm{PaO}_{2}$ : arterial oxygen tension; $\mathrm{PaCO}_{2}$ : arterial carbon dioxide tension; ANOVA: analysis of variance. Significantly different from non FL group. *: p<0.05; **: $\mathrm{p}<0.01 ; * * *: \mathrm{p}<0.001$.

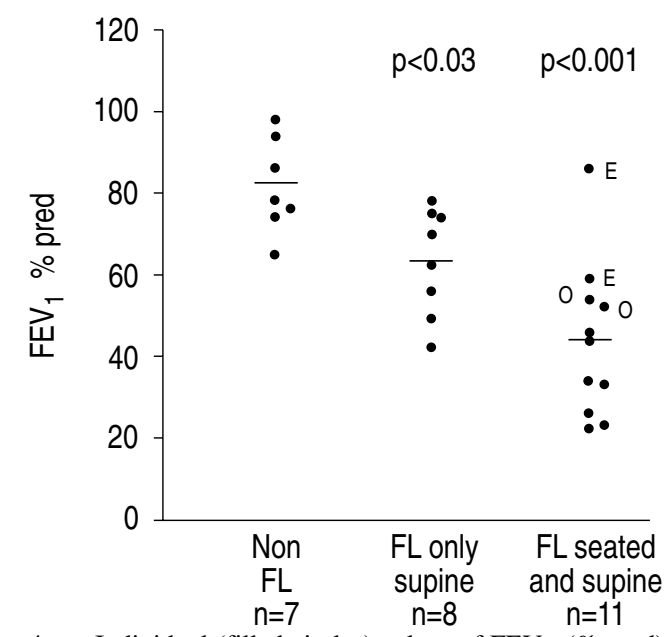

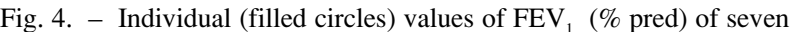
COPD patients who at rest were not flow-limited either seated or supine, eight who were flow-limited only supine, and 11 who were flow-limited both rested and supine. FL: flow-limited; E: elderly; O: obese; FEV : forced expiratory volume in one second; COPD: chronic obstructive pulmonary disease; $\%$ pred: percentage of predicted. $p$ values indicate significantly different from non FL group.
The average $( \pm \mathrm{SD})$ anthropometric and lung function data in sitting position of these three groups of patients are given in table 1. Whilst the anthropometric variables did not differ significantly among the groups, the lung function data were significantly better in the non-flowlimited group, and worst in the patients who were flowlimited both seated and supine. The individual values of $\mathrm{FEV}_{1}$ (\% pred) for the three groups are shown in figure 4. Though the patients who were flow-limited both seated and supine tended to have the most severe respiratory impairment, four of them had relatively well-preserved lung function (three with moderate and one with no ventilatory impairment). Two of these patients were rather old (73 and $75 \mathrm{yrs}$ ), whilst the other two were overweight (147 and $156 \%$ pred).

Expiratory flow limitation was also assessed in sitting position by comparing the resting expiratory $\dot{\mathrm{V}}-\mathrm{V}$ curves with the maximal expiratory flow-volume curves. Assuming that, at comparable lung volumes, similar or higher flows during resting expiration than during the FVC manoeuvre reflect expiratory flow-limitation (types 2 and 3 in figure 5), 16 of our 26 COPD patients would have been classified

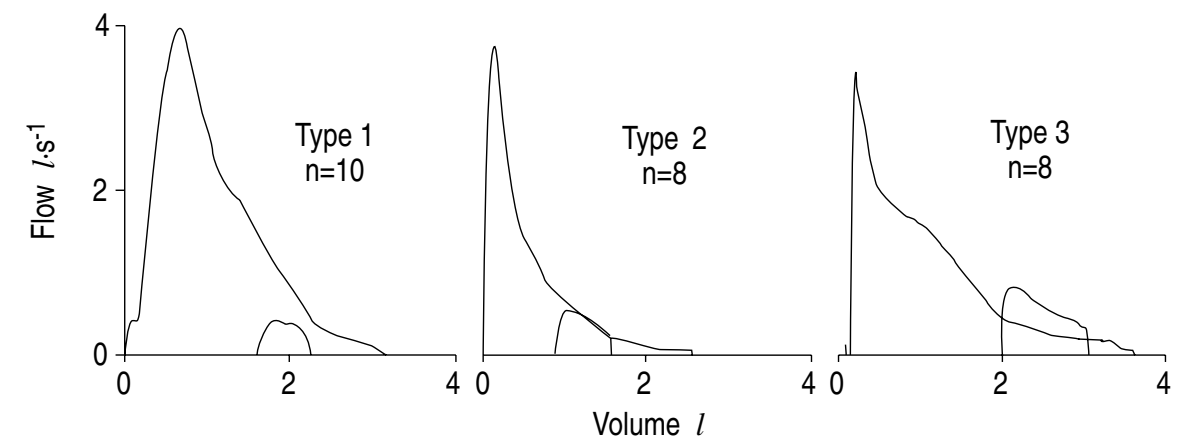

Fig. 5. - Expiratory flow-volume curves obtained at rest and during forced vital capacity (FVC) manoeuvres while sitting in body plethysmograph. In type 1 resting flows are lower, in type 2 superimposed, and in type 3 higher than those obtained during FVC manoeuvre. 
as flow-limited. In contrast, only 11 of these patients were classified as flow-limited in seated position on the basis of the NEP method (fig. 4). This discrepancy occurred only in type 2 patients.

\section{Discussion}

The main findings of the present study are: 1) that NEP provides a simple, rapid, noninvasive method for detection of expiratory flow-limitation in spontaneously breathing patients; 2) that expiratory flow-limitation during resting breathing is quite common in patients with mild-to-moderate COPD, particularly in supine position; and 3) that the conventional method for detecting expiratory flow limitation by comparison of tidal and maximal $\dot{V}-\mathrm{V}$ curves often leads to erroneous conclusions.

The NEP method has previously been used in ICU patients during controlled mechanical ventilation by VALTA et al. [13], who also validated this method by comparing the NEP results with those obtained from direct measurement of isovolume $\dot{V}$-P relationships. In the present study, we have extended the NEP method to stable, spontaneously breathing COPD patients.

In our COPD patients, application of NEP was not associated with unpleasant sensations, and on only one occasion did NEP cause mobilization of tracheobronchial secretions, resulting in cough. SuRATT et al. [18] measured the ability of the pharyngeal airway to resist collapse from subatmospheric pressure applied to the nose in awake supine patients with obstructive sleep apnoeas (OSA). They found that the pressures required to produce collapse ranged from -11 to $-40 \mathrm{cmH}_{2} \mathrm{O}$, which is considerably more subatmospheric than our NEP (-5 $\left.\mathrm{cmH}_{2} \mathrm{O}\right)$. Furthermore, none of our patients had a history of OSA or any evidence of upper airway obstruction. It is unlikely that the application of NEP elicited

a)

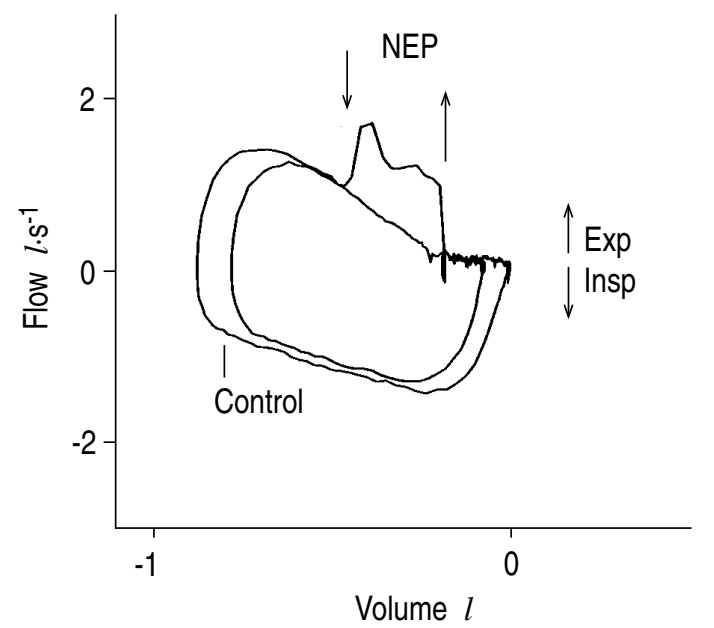

significant activity of expiratory and upper airway muscles, because after the application of short NEP pulses, the expiratory flow returned rapidly to the preceding control values (fig. 6). Similar results were obtained by O'Donnell et al. (see fig. 3 [8]).

Application of NEP during expiration increases the pressure gradient between the alveoli and the airway opening [13]. Accordingly, in non-flow-limited subjects, the expiratory flow should increase with NEP throughout the tidal expiration, as shown in figure 2. By contrast, in flow-limited patients, application of NEP should enhance dynamic airway compression downstream from the flow-limiting segments, without substantial effects on pressure or flow upstream. Indeed, in our flowlimited patients, there was no increase in flow with NEP, except for an early transient increase in flow (fig. 3). Such flow transients are probably due to two main mechanisms.

Firstly, during spontaneous breathing there is postinspiratory activity (PIA) of the inspiratory muscles during the initial part of expiration, which counterbalances the elastic recoil pressure stored in the respiratory system during the preceding inspiration; and, hence, exerts an expiratory braking action [19-21]. As a result, the flow during spontaneous expiration increases slowly to its peak value, whereas during relaxed (passive) expiration it peaks very rapidly [22, 23]. Although, in COPD patients, the postinspiratory activity of the diaphragm decays faster than in normal subjects [24], PIA nevertheless delays the attainment of maximal tidal flows, as indicated by the fact that peak expiratory flow during the control breath is not reached at the outset of expiration (figs 2 and 3). An increasing flow at the onset of expiration implies absence of flow limitation. Thus, early application of NEP in spontaneously breathing COPD patients should counterbalance the braking action of PIA, and result in an increase of expiratory flow, whether the

b)

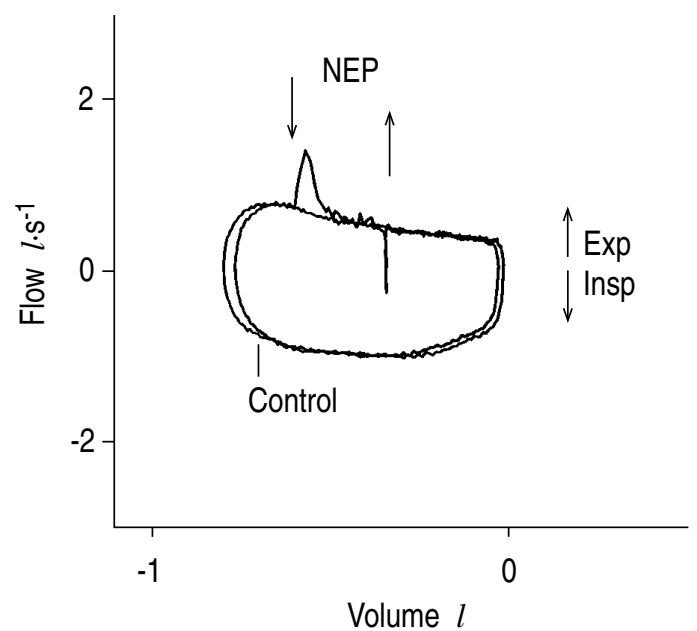

Fig. 6. - a) A flow-volume loop during which negative pressure (NEP) was applied over the middle part of expiration (between 2 arrows) in a seated COPD patient at rest, together with the preceding control loop. During the application of NEP, there was a sustained increase of flow, indicating that the patient was not flow-limited during the control expiration. After removal of NEP, expiratory flow returned rapidly to control. b) Similar loops to those in (a) in another seated COPD patient at rest. Application of a NEP pulse caused only a transient increase of flow, followed by return to control values while NEP was still being applied, indicating that the patient was flow-limited. When NEP was removed, the expiratory flow-volume relationship was the same as under control conditions. For further explanations see text. For abbreviations see legend to figure 2 . 
patient is flow-limited or not, during the ensuing part of expiration.

Secondly, application of NEP necessarily causes a reduction in volume of the upper airways, mainly in the compliant oral and neck structures [25]. This gas volume displacement contributes in part to the initial flow transient following application of NEP. Based on these considerations, it is evident that in spontaneously breathing patients, expiratory flow limitation cannot be present over the entire control expiration. In our patients, when present, flow-limitation encompassed $40-82 \%$ of the latter part of the tidal expiration.

With the NEP technique, expiratory flow limitation in seated and/or supine position was present in 19 (73\%) of our 26 patients. In eight patients, flow limitation was present in supine but not in sitting position, probably mainly reflecting the fact that in supine position there is a reduction in functional residual capacity (FRC) with a concomitant decrease in expiratory flow reserve. As a result, expiratory flow limitation at rest should be an earlier manifestation of COPD in supine than in sitting position. Indeed, all 11 COPD patients who were found to be flow-limited whilst seated were also flow-limited when supine, suggesting that as COPD becomes more severe flow limitation progresses from supine to seated position. However, it is important to note that four of the patients who were flow-limited both sitting and supine, had moderate or no ventilatory impairment at all (two with advanced age and two with increased body weight) (fig. 4). With advancing age, the maximum expiratory flows decrease, particularly at low lung volumes [26]. As a result, even in normal elderly subjects expiratory flow limitation may be present at rest, particularly in supine position [27, 28]. This phenomenon may also occur in overweight subjects, because of a reduction both in FRC and maximal expiratory flows [29]. Thus, expiratory flow limitation during resting breathing in supine elderly and/or obese subjects may well be a rather common phenomenon, which is not limited to COPD patients.

The presence of expiratory flow limitation at rest implies the presence of dynamic pulmonary hyperinflation and PEEPi [4]. The latter should be enhanced by increased ventilation due to muscular activity or other mechanisms. Accordingly, in patients who are flow-limited at rest, the exercise reserve should be severely limited. In this connection, it should be stressed that expiratory flow limitation, with the concomitant dynamic hyperinflation and PEEPi, is the major cause of acute ventilatory failure in COPD patients [30]. It should also be noted that in spontaneously breathing patients, assessment of PEEPi is difficult, requiring measurement of oesophageal and gastric pressures $[7,31]$. In contrast, detection of expiratory flow limitation with the NEP method is simpler, as well as noninvasive.

Pulmonary hyperinflation is defined as an increase of FRC above predicted normal. This may be due to an increase in the relaxation volume (Vr) of the respiratory system as a result of loss of lung elastic recoil (e.g. emphysema), or to dynamic pulmonary hyperinflation, which is said to be present when FRC exceeds $\operatorname{Vr}$ [32].
Predictably, the group of patients who exhibited expiratory flow limitation in sitting position had the highest FRC (\% pred) (table 1$)$, which probably reflected in part an increase in $\mathrm{Vr}$, and in part the presence of flow limitation, in the sitting position in which FRC was measured. The group of patients who exhibited expiratory flow limitation only supine, also presented a moderate increase of FRC in sitting position. In this case, the hyperinflation presumably reflected an increase of $\mathrm{Vr}$. It should be noted, however, that some degree of dynamic pulmonary hyperinflation may also be present in the absence of expiratory flow limitation [32].

In a study of 96 seated patients with stable COPD, a significant association has been found between the levels of $\mathrm{PaCO}_{2}$ and PEEPi [5]. Since PEEPi is a manifestation of expiratory flow limitation, one might have expected a significant increase in $\mathrm{PaCO}_{2}$ in our patients who were flow-limited in sitting position. However, whilst their average $\mathrm{PaCO}_{2}$ was higher than that of the patients who were not flow-limited, the difference was not significant (table 1). This may reflect the small number of patients in whom the values of $\mathrm{PaCO}_{2}$ were available. It should be noted, however, that the values of $\mathrm{PaO}_{2}$ were significantly lower in the COPD patients who were flow-limited both seated and supine.

Based on comparison of tidal and maximal $\dot{\mathrm{V}}-\mathrm{V}$ curves, 16 of our COPD patients should have been classified as flow-limited in seated position (fig. 5). By contrast, according to the NEP method, flow limitation in sitting position was present in only 11 of these patients (fig. 4). This discrepancy may be due to several factors:

Firstly, using the body plethysmographic technique, INGRAM and SCHILDER [9] have shown that during the FVC manoeuvre there is considerable compression of gas within the thorax. As a result, during the FVC manoeuvre the actual thoracic gas volume (TGV) may differ substantially from the corresponding exhaled volume obtained either by spirometry or by integration of the pneumotachographic flow signal $[9,33]$. Although the article by INGRAM and SCHILDER [9] was published as early as 1966, nearly all clinical and many research laboratories still use expired gas volume for determination of flow-volume curves. The inherent gas compression artifact, however, is an important and vexing source of variability and confusion.

Based on these considerations, it is clearly implied that comparison of tidal and maximal $\dot{V}-\mathrm{V}$ curves should be based on body plethysmographic volumes. It can also be argued that if the $\dot{\mathrm{V}}-\mathrm{V}$ curves of the type 2 patients of figure 5 had been based on TGV instead of expired volume, the maximal $\dot{\mathrm{V}}-\mathrm{V}$ curves would have been displaced to the right as a result of gas compression, and, consequently, the tidal and maximal $\dot{\mathrm{V}}-\mathrm{V}$ curves would no longer be superimposed, indicating that actually there was no flow limitation. This is supported by the fact that in five of the eight type 2 patients we found no evidence of flow limitation using the NEP method.

Based on the above discussions, it can be concluded that comparison of tidal and maximal $\dot{\mathrm{V}}-\mathrm{V}$ curves requires a body plethysmograph [9]. With the plethysmograph, however, such measurements can be made only in the 
seated position at rest. By contrast, the NEP method can be used in any position, both at rest and during increased ventilation [34].

Secondly comparison of tidal and maximal expiratory $\dot{\mathrm{V}}-\mathrm{V}$ relationships has another important limitation, because, by definition, the volume and time history preceding the tidal expiration is different from the volume and time history preceding the FVC manoeuvre. FAIRSHTER [10] has shown that in COPD patients inhalation to total lung capacity (TLC) is associated with a decrease in specific airway resistance and static lung recoil pressure. The fact that lung mechanics are different during the tidal and maximal expiratory efforts makes comparison of the two $\dot{\mathrm{V}}-\mathrm{V}$ curves problematical. Time constant inequality within the lungs, which is a characteristic feature of COPD patients, may also affect the maximal and tidal $\dot{\mathrm{V}}-\mathrm{V}$ relationships differently [11]. Furthermore, a recent study has shown that in COPD patients the speed of inspiration to TLC and the duration of breathholding at TLC have a profound effect on the magnitude of the flows during the subsequent FVC manoeuvre [12].

It is evident, therefore, that detection of expiratory flow limitation based on comparison of tidal and maximal $\dot{\mathrm{V}}-\mathrm{V}$ curves is problematical even if volume is measured with a body plethysmograph. For example, depending on the time course of the previous inspiratory manoeuvre, the maximal $\dot{\mathrm{V}}-\mathrm{V}$ curve may be below or above the tidal $\dot{V}-\mathrm{V}$ curve. This may explain why in three of our eight type 2 patients we found evidence of expiratory flow limitation with the NEP method, though this should have been absent considering the thoracic gas compression artifact during the FVC manoeuvre (see above). It is highly likely that in these three patients the FVC manoeuvre was performed after a slow inspiration to TLC associated with a relatively long end-inspiratory breathhold, resulting in low maximal expiratory flows [12]. In this connection, it should be noted that similar considerations pertain to comparison of tidal $\dot{\mathrm{V}}-\mathrm{V}$ curves with those obtained during partial forced expirations. Indeed, WeLLMAN et al. [35] have shown that in normal subjects the maximal flows obtained during a forced expiratory manoeuvre started from FRC depend on the previous volume history, similar to the FVC manoeuvres. By contrast, with the NEP method, the previous volume history is by definition fixed (figs 2 and 3 ). In this connection, it should also be noted that performance of complete and partial forced expiratory manoeuvres requires full understanding, skill and co-operation from patients, conditions which often are not fulfilled.

In conclusion, the application of NEP provides a simple, rapid, noninvasive method to detect expiratory flow limitation during spontaneous breathing, which does not require a body plethysmograph and the patient's cooperation. It can be applied in different body positions, both at rest and during muscular exercise.

Acknowledgements: The authors wish to thank the respiratory technicians of the Pulmonary Function Laboratory of the Saint-Luc Hospital for valuable co-operation. They also thank M. Makroyanni for typing this manuscript and H. Ghezzo for help with statistical analysis.

\section{References}

1. Hyatt RE. The interrelationship of pressure, flow and volume during various respiratory maneuvers in normal and emphysematous patients. Am Rev Respir Dis 1961; 83: 676-683.

2. Potter WA, Olafsson S, Hyatt R. Ventilatory mechanics and expiratory flow limitation during exercise in patients with obstructive lung disease. J Clin Invest 1971; 50: 910-919.

3. Pride N, Macklem PT. Lung mechanics in disease. In: Macklem PT, Mead J, eds. The Handbook of Physiology. Section 3. The Respiratory System. Vol. III, Part 2, Chp. 37. Bethesda, American Physiological Society, 1986; pp. 659-692.

4. Rossi A, Gottfried SB, Zocchi L, et al. Measurement of static compliance of the total respiratory system in patients with acute respiratory failure during mechanical ventilation. Am Rev Respir Dis 1985; 131: 672677.

5. Haluszka J, Chartrand DA, Grassino AE, Milic-Emili J. Intrinsic PEEP and arterial $\mathrm{PCO}_{2}$ in stable patients with chronic obstructive pulmonary disease. Am Rev Respir Dis 1990; 141: 1194-1197.

6. Aldrich TK, Hendler JM, Vizioli LD, Park M, Multz AS, Shapiro SM. Intrinsic positive end-expiratory pressure in ambulatory patients with airways obstruction. Am Rev Respir Dis 1993; 147: 845-849.

7. Appendini L, Potassio A, Zanaboni S, et al. Physiologic effects of positive end-expiratory pressure and mask pressure support during exacerbations of chronic obstructive pulmonary disease. Am J Respir Crit Care Med 1994; 149: 1069-1076.

8. O'Donnell DE, Sanii R, Anthonisen NR, Younes M. Effect of dynamic airway compression on breathing pattern and respiratory sensation in severe chronic obstructive pulmonary disease. Am Rev Respir Dis 1987; 135: 912-918.

9. Ingram RH Jr, Schilder DP. Effect of gas compression on pulmonary pressure, flow, and volume relationship. J Appl Physiol 1966; 21: 1821-1826.

10. Fairshter RD. Airway hysteresis in normal subjects and individuals with chronic airflow obstruction. J Appl Physiol 1985; 58: 1505-1510.

11. Melissinos CG, Webster P, Tien YK, Mead J. Time dependence of maximum flow as an index of nonuniform emptying. J Appl Physiol: Respirat Environ Exercise Physiol 1979; 47: 1043-1050.

12. D'Angelo E, Prandi E, Marazzini L, Milic-Emili J. Dependence of maximal flow-volume curves on time course of preceding inspiration in patients with chronic obstructive lung disease. Am J Respir Crit Care Med 1994; 150 : $1581-1586$.

13. Valta P, Corbeil C, Lavoie A, et al. Detection of expiratory flow limitation during mechanical ventilation. Am J Respir Crit Care Med 1994; 150: 1311-1317.

14. Scientific Tables, Documenta Geigy. In: Diem K, Lentner C, eds. Basle, Switzerland, J.R. Geigy, S.A., 1970, p. 711.

15. Morris JF, Koski A, Johnson LC. Spirometric standards for healthy nonsmoking adults. Am Rev Respir Dis 1971; 103: 57-67.

16. Farré R, Navajas D, Peslin R, Rotger M, Duvivier C. A correction procedure for the asymmetry of differential pressure transducers in respiratory impedance measurements. IEEE Trans Biomed Eng 1989; 36: 1137-1140.

17. Peslin R, Felicio da Silva J, Chabot F, Duvivier C. Respiratory mechanics studied by multiple linear regression 
in unsedated ventilated patients. Eur Respir J 1992; 5: 871-878.

18. Suratt PM, Wilhoit SC, Cooper K. Induction of airway collapse with subatmospheric pressure in awake patients with sleep apnea. J Appl Physiol: Respirat Environ Exercise Physiol 1984; 57: 140-146.

19. Green JH, Howell JBL. Correlation of intercostal muscle activity with respiratory airflow in conscious human subjects. J Physiol (Lond) 1959; 149: 471-476.

20. Petit JM, Milic-Emili J, Delhez L. Role of the diaphragm in breathing in conscious normal man: an electromyographic study. J Appl Physiol 1960; 15: 1101- 1106.

21. Shee CD, Ploy-song-sang Y, Milic-Emili J. Decay of inspiratory muscle pressure during expiration in conscious humans. J Appl Physiol 1985; 58: 18591865.

22. Morris MJ, Lane DJ. Tidal expiratory flow patterns in airflow obstruction. Thorax 1981; 36: 135-142.

23. Milic-Emili J, Zin WA. Relationship between neuromuscular respiratory drive and ventilatory output. In: Macklem PT, Mead J, eds. The Handbook of Physiology. Section 3. The Respiratory System. Vol. III, Part 2, Chp. 35. Bethesda, American Physiological Society, 1986; pp. 631-646.

24. Citterio G, Agostoni E, Del Santo A, Marazzini L. Decay of inspiratory muscle activity in chronic airway obstruction. J Appl Physiol: Respirat Environ Exercise Physiol 1981; 51: 1388-1397.

25. Jaeger MJ. Effect of the cheeks and the compliance of alveolar gas on the measurement of respiratory variables. Respir Physiol 1982; 47: 325-340.

26. Knudson RJ, Clark DF, Kennedy TC, Knudson DE. Effect of aging alone on mechanical properties of the normal adult human lung. J Appl Physiol: Respirat Environ Exercise Physiol 1977; 43: 1054-1062.

27. Brulot N, Kadas V, Grassino A, Milic-Emili J. Positional variation in lung volumes in COPD. Am Rev Respir Dis 1992; 145: A764 (Abstract).

28. Milic-Emili J. Respiratory mechanics in chest wall disease: implications for expiratory flow limitation during resting breathing. Monaldi Arch Chest Dis 1993; 1: 80-82.

29. Zarah F, Harf A, Perlemuter L, Lorino H, Lorino AM, Atlan G. Effects of obesity on respiratory resistance. Chest 1993; 103 : 1470-1476.

30. Coussa ML, Guérin C, Eissa NT, et al. Partitioning of work of breathing in mechanically ventilated COPD patients. J Appl Physiol 1993; 75: 1711-1719.

31. Ninane V, Yernault J-C, DeTroyer A. Intrinsic PEEP in patients with chronic obstructive pulmonary disease. Am Rev Respir Dis 1993; 148: 1037-1042.

32. Milic-Emili J. Intrinsic PEEP. In: Yearbook of Intensive Care and Emergency Medicine. Berlin, Springer-Verlag, 1994; pp. 477-481.

33. Rodarte JR, Rehder K. Dynamics of respiration. In: Macklem PT, Mead J, eds. The Respiratory System; Mechanics of Breathing. Part 1. Bethesda, American Physiological Society, 1986; pp. 131-144.

34. Koulouris N, Valta P, Dimopoulou I, Finkelstein R, Cosio MG, Milic-Emili J. A simple technique to detect expiratory flow limitation at rest and during exercise (Abstract). Eur Respir J 1993; 6 (Suppl. 17): 1344.

35. Wellman, JJ, Brown R, Ingram RH Jr, Mead J, McFadden ER. Effect of volume history on successive partial expiratory flow-volume maneuvers. J Appl Physiol 1976; 41: $153-158$. 